\title{
Fuzzy Hyers-Ulam stability of an additive functional equation
}

\author{
Hassan Azadi Kenary ${ }^{1}$, Hamid Rezaei ${ }^{1}$, Anoshiravan Ghaffaripour ${ }^{1}$, Saedeh Talebzadeh², Choonkil Park $^{3}$ and \\ Jung Rye Lee ${ }^{4^{*}}$
}

* Correspondence: jrlee@daejin.ac. $\mathrm{kr}$

${ }^{4}$ Department of Mathematics, Daejin University, Kyeonggi 487711, Korea

Full list of author information is available at the end of the article

\section{Abstract}

In this paper, using the fixed point and direct methods, we prove the Hyers-Ulam stability of the following additive functional equation

$$
2 f\left(\frac{x+y+z}{2}\right)=f(x)+f(y)+f(z)
$$

in fuzzy normed spaces.

Mathematics Subject Classification (2010): 39B22; 39B52; 39B82; 46S10; 47S10; $46 S 40$.

Keywords: Hyers-Ulam stability, additive functional equation, fuzzy normed space

\section{Introduction}

A classical question in the theory of functional equations is the following: When is it true that a function which approximately satisfies a functional equation must be close to an exact solution of the equation? If the problem accepts a solution, we say that the equation is stable. The first stability problem concerning group homomorphisms was raised by Ulam [1] in 1940. In the next year, Hyers [2] gave a positive answer to the above question for additive groups under the assumption that the groups are Banach spaces. In 1978, Rassias [3] proved a generalization of the Hyers' theorem for additive mappings.

Theorem 1.1. (Th.M. Rassias) Let $f: X \rightarrow Y$ be a mapping from a normed vector space $X$ into a Banach space $Y$ subject to the inequality

$$
\|f(x+y)-f(x)-f(y)\| \leq \varepsilon\left(\|x\|^{p}+\|y\|^{p}\right)
$$

for all $x, y \in X$, where $\varepsilon$ and $p$ are constants with $\varepsilon>0$ and $0 \leq p<1$. Then the limit

$$
L(x)=\lim _{n \rightarrow \infty} \frac{f\left(2^{n} x\right)}{2^{n}}
$$

exists for all $x \in X$ and $L: X \rightarrow Y$ is the unique additive mapping which satisfies

$$
\|f(x)+L(x)\| \leq \frac{2 \varepsilon}{2-2^{p}}\|x\|^{p}
$$

for all $x \in X$. Also, if for each $x \in X$, the function $f(t x)$ is continuous in $t \in \mathbb{R}$, then $L$ is $\mathbb{R}$-linear. 
Furthermore, in 1994, a generalization of Rassias' theorem was obtained by Găvruta [4] by replacing the bound $\varepsilon\left(\|x\|^{p}+\|y\|^{p}\right)$ by a general control function $\phi(x, y)$.

In 1983, a Hyers-Ulam stability problem for the quadratic functional equation was proved by Skof [5] for mappings $f: X \rightarrow Y$, where $X$ is a normed space and $Y$ is a Banach space. In 1984, Cholewa [6] noticed that the theorem of Skof is still true if the relevant domain $X$ is replaced by an Abelian group and, in 2002, Czerwik [7] proved the HyersUlam stability of the quadratic functional equation. The reader is referred to ([8-20]) and references therein for detailed information on stability of functional equations.

Katsaras [21] defined a fuzzy norm on a vector space to construct a fuzzy vector topological structure on the space. Some mathematicians have defined fuzzy norms on a vector space from various points of view (see $[22,23])$. In particular, Bag and Samanta [24], following Cheng and Mordeson [25], gave an idea of fuzzy norm in such a manner that the corresponding fuzzy metric is of Karmosil and Michalek type [26]. They established a decomposition theorem of a fuzzy norm into a family of crisp norms and investigated some properties of fuzzy normed spaces [27].

Definition 1.2. Let $X$ be a real vector space. A function $N: X \times \mathbb{R} \rightarrow[0,1]$ is called a fuzzy norm on $X$ if for all $x, y \in X$ and all $s, t \in \mathbb{R}$,

(N1) $N(x, t)=0$ for $t \leq 0$;

(N2) $x=0$ if and only if $N(x, t)=1$ for all $t>0$;

(N3) $N(c x, t)=N\left(x, \frac{t}{|c|}\right)$ if $c \neq 0$;

(N4) $N(x+y, c+t) \geq \min \{N(x, s), N(y, t)\}$;

(N5) $N(x,$.$) is a non-decreasing function of \mathbb{R}$ and $\lim _{t \rightarrow \infty} N(x, t)=1$;

(N6) for $x \neq 0, N(x,$.$) is continuous on \mathbb{R}$.

The pair $(X, N)$ is called a fuzzy normed vector space.

Example 1.3. Let $(X,\|\|$.$) be a normed linear space and \alpha, \beta>0$. Then

$$
N(x, t)= \begin{cases}\frac{\alpha t}{\alpha t+\beta\|x\|} t>0, x \in X \\ 0 \quad t \leq 0, x \in X\end{cases}
$$

is a fuzzy norm on $X$.

Definition 1.4. Let $(X, N)$ be a fuzzy normed vector space. A sequence $\left\{x_{n}\right\}$ in $X$ is said to be convergent or converge if there exists an $x \in X$ such that $\lim _{t \rightarrow \infty} N\left(x_{n}-x, t\right)$ $=1$ for all $t>0$. In this case, $x$ is called the limit of the sequence $\left\{x_{n}\right\}$ in $X$ and we denote it by $N-\lim _{t \rightarrow \infty} x_{n}=x$.

Definition 1.5. Let $(X, N)$ be a fuzzy normed vector space. A sequence $\left\{x_{n}\right\}$ in $X$ is called Cauchy if for each $\varepsilon>0$ and each $t>0$ there exists an $n_{0} \in \mathbb{N}$ such that for all $n \geq n_{0}$ and all $p>0$, we have $N\left(x_{n+p}-x_{n}, t\right)>1-\varepsilon$.

It is well known that every convergent sequence in a fuzzy normed vector space is Cauchy. If each Cauchy sequence is convergent, then the fuzzy norm is said to be complete and the fuzzy normed vector space is called a fuzzy Banach space.

We say that a mapping $f: X \rightarrow Y$ between fuzzy normed vector spaces $X$ and $Y$ is continuous at a point $x \in X$ if for each sequence $\left\{x_{n}\right\}$ converging to $x_{0} \in X$, then the sequence $\left\{f\left(x_{n}\right)\right\}$ converges to $f\left(x_{0}\right)$. If $f: X \rightarrow Y$ is continuous at each $x \in X$, then $f: X$ $\rightarrow Y$ is said to be continuous on $X$.

Definition 1.6. Let $X$ be a set. A function $d: X \times X \rightarrow[0, \infty]$ is called a generalized metric on $X$ if $d$ satisfies the following conditions: 
(a) $d(x, y)=0$ if and only if $x=y$ for all $x, y \in X$;

(b) $d(x, y)=d(y, x)$ for all $x, y \in X$;

(c) $d(x, z) \leq d(x, y)+d(y, z)$ for all $x, y, z \in X$.

Theorem 1.7. ([28,29]) Let $(X, d)$ be a complete generalized metric space and $J: X \rightarrow$ $X$ be a strictly contractive mapping with Lipschitz constant $L<1$. Then, for all $x \in X$, either $d\left(J^{n} x, J^{n+1} x\right)=\infty$ for all nonnegative integers $n$ or there exists a positive integer $n_{0}$ such that

(a) $d\left(J^{n} x, J^{n+1} x\right)<\infty$ for all $n_{0} \geq n_{0}$;

(b) the sequence $\left\{J^{n} x\right\}$ converges to a fixed point $y^{*}$ of $J$;

(c) $y^{*}$ is the unique fixed point of $J$ in the set $Y=\left\{y \in X: d\left(J^{n_{0}} x, y\right)<\infty\right\}$;

(d) $d\left(y, y^{*}\right) \leq \frac{d(y, J y)}{1-L}$ for all $y \in Y$.

\section{Fuzzy stability of the functional Eq. (0.1)}

Throughout this section, using the fixed point and direct methods, we prove the Hyers-Ulam stability of functional Eq. (0.1) in fuzzy normed spaces.

\subsection{Fixed point alternative approach}

Throughout this subsection, using the fixed point alternative approach, we prove the Hyers-Ulam stability of functional Eq. (0.1) in fuzzy Banach spaces.

In this subsection, assume that $X$ is a vector space and that $(Y, N)$ is a fuzzy Banach space.

Theorem 2.1. Let $\phi: X^{3} \rightarrow[0, \infty)$ be a function such that there exists an $L<1$ with

$$
\varphi(x, y, z) \leq \frac{L \varphi(2 x, 2 y, 2 z)}{2}
$$

for all $x, y, z \in X$. Let $f: X \rightarrow Y$ be a mapping satisfying

$$
N\left(2 f\left(\frac{x+y+z}{2}\right)-f(x)-f(y)-f(z), t\right) \geq \frac{t}{t+\varphi(x, y, z)}
$$

for all $x, y, z \in X$ and all $t>0$. Then the limit

$$
A(x):=N-\lim _{n \rightarrow \infty} 2^{n} f\left(\frac{x}{2^{n}}\right)
$$

exists for each $x \in X$ and defines a unique additive mapping $A: X \rightarrow Y$ such that

$$
N(f(x)-A(x), t) \geq \frac{(2-2 L) t}{(2-2 L) t+L \varphi(x, 2 x, x)} .
$$

Proof. Putting $y=2 x$ and $z=x$ in (2.1) and replacing $x$ by $\frac{x}{2}$, we have

$$
N\left(2 f\left(\frac{x}{2}\right)-f(x), t\right) \geq \frac{t}{t+\varphi\left(\frac{x}{2}, x, \frac{x}{2}\right)}
$$

for all $x \in X$ and $t>0$. Consider the set

$$
S:=\{g: X \rightarrow Y\}
$$


and the generalized metric $d$ in $S$ defined by

$$
d(f, g)=\inf \left\{\mu \in \mathbb{R}^{+}: N(g(x)-h(x), \mu t) \geq \frac{t}{t+\varphi(x, 2 x, x)}, \forall x \in X, t>0\right\},
$$

where inf $\varnothing=+\infty$. It is easy to show that $(S, d)$ is complete (see [30, Lemma 2.1]). Now, we consider a linear mapping $J: S \rightarrow S$ such that

$$
J g(x):=2 g\left(\frac{x}{2}\right)
$$

for all $x \in X$. Let $g, h \in S$ be such that $d(g, h)=\varepsilon$. Then

$$
N(g(x)-h(x), \varepsilon t) \geq \frac{t}{t+\varphi(x, 2 x, x)}
$$

for all $x \in X$ and $t>0$. Hence,

$$
\begin{aligned}
N(J g(x)-J h(x), L \varepsilon t) & =N\left(2 g\left(\frac{x}{2}\right)-2 h\left(\frac{x}{2}\right), L \varepsilon t\right) \\
& =N\left(g\left(\frac{x}{2}\right)-h\left(\frac{x}{2}\right), \frac{L \varepsilon t}{2}\right) \\
& \geq \frac{\frac{L t}{2}}{\frac{L t}{2}+\varphi\left(\frac{x}{2}, x, \frac{x}{2}\right)} \\
& \geq \frac{\frac{L t}{2}}{\frac{L t}{2}+\frac{L \varphi(x, 2 x, x)}{2}} \\
& =\frac{t}{t+\varphi(x, 2 x, x)}
\end{aligned}
$$

for all $x \in X$ and $t>0$. Thus, $d(g, h)=\varepsilon$ implies that $d(J g, J h) \leq L \varepsilon$. This means that

$$
d(J g, J h) \leq L d(g, h)
$$

for all $g, h \in S$. It follows from (2.3) that

$$
\begin{aligned}
N\left(f(x)-2 f\left(\frac{x}{2}\right), t\right) \geq \frac{t}{t+\varphi\left(\frac{x}{2}, x, \frac{x}{2}\right)} & \geq \frac{t}{t+\frac{L \varphi(x, 2 x, x)}{2}} \\
& =\frac{\frac{2 t}{L}}{\frac{2 t}{L}+\varphi(x 2 x, x)}
\end{aligned}
$$

Therefore,

$$
N\left(f(x)-2 f\left(\frac{x}{2}\right), \frac{L t}{2}\right) \geq \frac{t}{t+\varphi(x, 2 x, x)} .
$$

This means that

$$
d(f, \text { Jf }) \leq \frac{L}{2} .
$$

By Theorem 1.7, there exists a mapping $A: X \rightarrow Y$ satisfying the following: 
(1) $A$ is a fixed point of $J$, that is,

$$
A\left(\frac{x}{2}\right)=\frac{A(x)}{2}
$$

for all $x \in X$. The mapping $A$ is a unique fixed point of $J$ in the set $\Omega=\{h \in S: d(g, h)<\infty\}$.

This implies that $A$ is a unique mapping satisfying (2.6) such that there exists $\mu$ $\in(0, \infty)$ satisfying

$$
N(f(x)-A(x), \mu t) \geq \frac{t}{t+\varphi(x, 2 x, x)}
$$

for all $x \in X$ and $t>0$.

(2) $d\left(J^{n} f, A\right) \rightarrow 0$ as $n \rightarrow \infty$. This implies the equality

$$
N-\lim _{n \rightarrow \infty} 2^{n} f\left(\frac{x}{2^{n}}\right)=A(x)
$$

for all $x \in X$.

(3) $d(f, A) \leq \frac{d(f, J f)}{1-L}$ with $f \in \Omega$, which implies the inequality

$$
d(f, A) \leq \frac{L}{2-2 L}
$$

This implies that the inequality (2.2) holds. Furthermore, since

$$
\begin{aligned}
& N\left(2 A\left(\frac{x+y+z}{2}\right)-A(x)-A(y)-A(z), t\right) \\
& \quad \geq N-\lim _{n \rightarrow \infty}\left(2^{n+1} f\left(\frac{x+y+z}{2^{n+1}}\right)-2^{n} f\left(\frac{x}{2^{n}}\right)-2^{n} f\left(\frac{y}{2^{n}}\right)-2^{n} f\left(\frac{z}{2^{n}}\right), t\right) \\
& \quad \geq \lim _{n \rightarrow \infty} \frac{\frac{t}{2^{n}}}{\frac{t}{2^{n}}+\frac{L^{n} \varphi(x, y, z)}{2^{n}}} \rightarrow 1
\end{aligned}
$$

for all $x, y, z \in X, t>0$. So $N\left(A\left(\frac{x+y+z}{2}\right)-A(x)-A(y)-A(z), t\right)=1$ for all $x, y, z \in$ $X$ and all $t>0$. Thus the mapping $A: X \rightarrow Y$ is additive, as desired.

Corollary 2.2. Let $\theta \geq 0$ and let $p$ be a real number with $p>1$. Let $X$ be a normed vector space with norm $\|$.$\| . Let f: X \rightarrow Y$ be a mapping satisfying

$$
N\left(2 f\left(\frac{x+y+z}{2}\right)-f(x)-f(y)-f(z), t\right) \geq \frac{t}{t+\theta\left(\|x\|^{p}+\|y\|^{p}+\|z\|^{p}\right)}
$$


for all $x, y, z \in X$ and all $t>0$. Then the limit

$$
A(x):=N-\lim _{n \rightarrow \infty} 2^{n} f\left(\frac{x}{2^{n}}\right)
$$

exists for each $x \in X$ and defines a unique additive mapping $A: X \rightarrow Y$ such that

$$
N(f(x)-A(x), t) \geq \frac{\left(2^{p}-1\right) t}{\left(2^{p}-1\right) t+\left(2^{r-1}+1\right) \theta\|x\|^{p}}
$$

for all $x \in X$.

Proof. The proof follows from Theorem 2.1 by taking $\phi(x, y, z):=\theta\left(\|x \mid\|^{p}+\|y\|^{p}+\right.$ $\|z\|^{p}$ ) for all $x, y, z \in X$. Then we can choose $L=2^{-p}$ and we get the desired result. 口

Theorem 2.3. Let $\phi: X^{3} \rightarrow[0, \infty)$ be a function such that there exists an $L<1$ with

$$
\varphi(2 x, 2 y, 2 z) \leq 2 L \varphi(x, y, z)
$$

for all $x, y, z \in X$. Let $f: X \rightarrow Y$ be a mapping satisfying (2.1). Then

$$
A(x):=N-\lim _{n \rightarrow \infty} \frac{f\left(2^{n} x\right)}{2^{n}}
$$

exists for each $x \in X$ and defines a unique additive mapping $A: X \rightarrow Y$ such that

$$
N(f(x)-A(x), t) \geq \frac{(2-2 L) t}{(2-2 L) t+\varphi(x, 2 x, x)}
$$

for all $x \in X$ and all $t>0$.

Proof. Let $(S, d)$ be the generalized metric space defined as in the proof of Theorem 2.1.

Consider the linear mapping $J: S \rightarrow S$ such that

$$
J(x):=\frac{g(2 x)}{2}
$$

for all $x \in X$. Let $g, h \in S$ be such that $d(g, h)=\varepsilon$. Then

$$
N(g(x)-h(x), \varepsilon t) \geq \frac{t}{t+\varphi(x, 2 x, x)}
$$

for all $x \in X$ and $t>0$. Hence,

$$
\begin{aligned}
N(J g(x)-J h(x), L \varepsilon t) & =N\left(\frac{g(2 x)}{2}-\frac{h(2 x)}{2}, L \varepsilon t\right) \\
& =N(g(2 x)-h(2 x), 2 L \varepsilon t) \\
& \geq \frac{2 L t}{2 L t+\varphi(2 x, 4 x, 2 x)} \\
& \geq \frac{2 L t}{2 L t+2 L \varphi(x, 2 x, x)} \\
& =\frac{t}{t+\varphi(x, 2 x, x)}
\end{aligned}
$$


for all $x \in X$ and $t>0$. Thus, $d(g, h)=\varepsilon$ implies that $d(J g, J h) \leq L \varepsilon$. This means that

$$
d(J g, J h) \leq L d(g, h)
$$

for all $g, h \in S$. It follows from (2.3) that

$$
N\left(\frac{f(2 x)}{2}-f(x), \frac{t}{2}\right) \geq \frac{t}{t+\varphi(x, 2 x, x)} .
$$

Therefore,

$$
d(f, J f) \leq \frac{1}{2} .
$$

By Theorem 1.7, there exists a mapping $A: X \rightarrow Y$ satisfying the following:

(1) $A$ is a fixed point of $J$, that is,

$$
2 A(x)=A(2 x)
$$

for all $x \in X$. The mapping $A$ is a unique fixed point of $J$ in the set $\Omega=\{h \in S: d(g, h)<\infty\}$.

This implies that $A$ is a unique mapping satisfying (2.8) such that there exists $\mu$ $\in(0, \infty)$ satisfying

$$
N(f(x)-A(x), \mu t) \geq \frac{t}{t+\varphi(x, 2 x, x)}
$$

for all $x \in X$ and $t>0$.

(2) $d\left(J^{n} f, A\right) \rightarrow 0$ as $n \rightarrow \infty$. This implies the equality

$$
N-\lim _{n \rightarrow \infty} \frac{f\left(2^{n} x\right)}{2^{n}}
$$

for all $x \in X$.

(3) $d(f, A) \leq \frac{d(f, f f)}{1-L}$ with $f \in \Omega$ which implies the inequality

$$
d(f, A) \leq \frac{1}{2-2 L}
$$

This implies that the inequality (2.7) holds.

The rest of the proof is similar to that of the proof of Theorem 2.1. 
Corollary 2.4. Let $\theta \geq 0$ and let $p$ be a real number with $0<p<\frac{1}{3}$. Let $X$ be a normed vector space with norm $\|$. $\|$. Let $f: X \rightarrow Y$ be a mapping satisfying

$$
N\left(2 f\left(\frac{x+y+z}{2}\right)-f(x)-f(y)-f(z), t\right) \geq \frac{t}{t+\theta\left(\|x\|^{p} .\|y\|^{p} \cdot\|z\|^{p}\right)}
$$

for all $x, y, z \in X$ and all $t>0$. Then

$$
A(x):=N-\lim _{n \rightarrow \infty} \frac{f\left(2^{n} x\right)}{2^{n}}
$$

exists for each $x \in \mathrm{X}$ and defines a unique additive mapping $A: X \rightarrow Y$ such that

$$
N(f(x)-A(x), t) \geq \frac{\left(2^{3 p}-1\right) t}{\left(2^{3 p}-1\right) t+2^{3 p-1} \theta\|x\|^{3 p}} .
$$

for all $x \in X$.

Proof. The proof follows from Theorem 2.3 by taking $\phi(x, y, z):=\theta\left(\|x\|^{p} \cdot\|y\|^{p} \cdot \|\right.$ $z \|^{p}$ ) for all $x, y, z \in X$. Then we can choose $L=2^{-3 p}$ and we get the desired result.

2.2. Direct method. In this subsection, using direct method, we prove the HyersUlam stability of the functional Eq. (0.1) in fuzzy Banach spaces.

Throughout this subsection, we assume that $X$ is a linear space, $(Y, N)$ is a fuzzy Banach space and $\left(Z, N^{\prime}\right)$ is a fuzzy normed spaces. Moreover, we assume that $N(x,$.$) is$ a left continuous function on $\mathbb{R}$.

Theorem 2.5. Assume that a mapping $f: X \rightarrow Y$ satisfies the inequality

$$
\begin{aligned}
& N\left(2 f\left(\frac{x+y+z}{2}\right)-f(x)-f(y)-f(z), t\right) \\
& \quad \geq N^{\prime}(\varphi(x, y, z), t)
\end{aligned}
$$

for all $x, y, z \in X, t>0$ and $\phi: X^{3} \rightarrow Z$ is a mapping for which there is a constant $r$ $\in \mathbb{R}$ satisfying $0<|r|<\frac{1}{2}$ and

$$
N^{\prime}(\varphi(x, y, z), t) \geq N^{\prime}\left(\varphi(2 x, 2 y, 2 z), \frac{t}{|r|}\right)
$$

for all $x, y, z \in X$ and all $t>0$. Then there exist a unique additive mapping $A: X \rightarrow$ $Y$ satisfying (0.1) and the inequality

$$
N(f(x)-A(x), t) \geq N^{\prime}\left(\varphi(x, 2 x, x), \frac{(1-2|r|) t}{|r|}\right)
$$

for all $x \in X$ and all $t>0$.

Proof. It follows from (2.10) that

$$
N^{\prime}\left(\varphi\left(\frac{x}{2^{j^{\prime}}}, \frac{y}{2^{j^{\prime}}}, \frac{z}{2^{j}}\right), t\right) \geq N^{\prime}\left(\varphi(x, y, z), \frac{t}{|r|^{j}}\right) .
$$

So

$$
N^{\prime}\left(\varphi\left(\frac{x}{2^{j}}, \frac{y}{2^{j}}, \frac{z}{2^{j}}\right),|r|^{j} t\right) \geq N^{\prime}(\varphi(x, y, z), t)
$$


for all $x, y, z \in X$ and all $t>0$. Substituting $y=2 x$ and $z=x$ in (2.9), we obtain

$$
N(f(2 x)-2 f(x), t) \geq N^{\prime}(\varphi(x, 2 x, x), t)
$$

So

$$
N\left(f(x)-2 f\left(\frac{x}{2}\right), t\right) \geq N^{\prime}\left(\varphi\left(\frac{x}{2}, x, \frac{x}{2}\right), t\right)
$$

for all $x \in X$ and all $t>0$. Replacing $x$ by $\frac{x}{2^{j}}$ in (2.14), we have

$$
\begin{aligned}
N\left(2^{j+1} f\left(\frac{x}{2^{j+1}}\right)-2^{j} f\left(\frac{x}{2^{j}}\right), 2^{j} t\right) & \geq N^{\prime}\left(\varphi\left(\frac{x}{2^{j+1}}, \frac{x}{2^{j}}, \frac{x}{2^{j+1}}\right), t\right) \\
& \geq N^{\prime}\left(\varphi(x, 2 x, x), \frac{t}{|r|^{j+1}}\right)
\end{aligned}
$$

for all $x \in X$, all $t>0$ and any integer $j \geq 0$. So

$$
\begin{aligned}
& N\left(f(x)-2^{n} f\left(\frac{x}{2^{n}}\right), \sum_{j=0}^{n-1} 2^{j}|r|^{j+1} t\right) \\
& =N\left(\sum_{j=0}^{n-1}\left[2^{j+1} f\left(\frac{x}{2^{j+1}}\right)-2^{j} f\left(\frac{x}{2^{j}}\right)\right], \sum_{j=0}^{n-1} 2^{j}|r|^{j+1} t\right) \\
& \quad \geq \min _{0 \leq j \leq n-1}\left\{N\left(2^{j+1} f\left(\frac{x}{2^{j+1}}\right)-2^{j} f\left(\frac{x}{2^{j}}\right), 2^{j}|r|^{j+1} t\right)\right\} \\
& \geq N^{\prime}(\varphi(x, 2 x, x), t) .
\end{aligned}
$$

Replacing $x$ by $\frac{x}{2^{p}}$ in the above inequality, we find that

$$
\begin{aligned}
N\left(2^{n+p} f\left(\frac{x}{2^{n+p}}\right)-2^{p} f\left(\frac{x}{2^{p}}\right), \sum_{j=0}^{n-1} 2^{j}|r|^{j+1} t\right) & \geq N^{\prime}\left(\varphi\left(\frac{x}{2^{p}}, \frac{2 x}{2^{p}}, \frac{x}{2^{p}}\right), t\right) \\
& \geq N^{\prime}\left(\varphi(x, 2 x, x), \frac{t}{|r| p}\right)
\end{aligned}
$$

for all $x \in X, t>0$ and all integers $n \geq 0, p \geq 0$. So

$$
N\left(2^{n+p} f\left(\frac{x}{2^{n+p}}\right)-2^{p} f\left(\frac{x}{2^{p}}\right), \sum_{j=0}^{n-1} 2^{j+p}|r|^{j+p+1} t\right) \geq N^{\prime}(\varphi(x, 2 x, x), t)
$$

for all $x \in X, t>0$ and all integers $n>0, p \geq 0$. Hence, one obtains

$$
N\left(2^{n+p} f\left(\frac{x}{2^{n+p}}\right)-2^{p} f\left(\frac{x}{2^{p}}\right), t\right) \geq N^{\prime}\left(\varphi(x, 2 x, x), \frac{t}{\sum_{j=0}^{n-1} 2^{j+p}|r|^{j+p+1}}\right)
$$

for all $x \in X, t>0$ and all integers $n>0, p \geq 0$. Since the series $\sum_{j=0}^{\infty} 2^{j}|r|^{j}$ is convergent, by taking the limit $p \rightarrow \infty$ in the last inequality, we know that a sequence $\left\{2^{n} f\left(\frac{x}{2^{n}}\right)\right\}$ is a Cauchy sequence in the fuzzy Banach space $(Y, N)$ and so it converges in $Y$. Therefore, a mapping $A: X \rightarrow Y$ defined by

$$
A(x):=N-\lim _{n \rightarrow \infty} 2^{n} f\left(\frac{x}{2^{n}}\right)
$$


is well defined for all $x \in X$. It means that

$$
\lim _{n \rightarrow \infty} N\left(A(x)-2^{n} f\left(\frac{x}{2^{n}}\right), t\right)=1
$$

for all $x \in X$ and all $t>0$. In addition, it follows from (2.17) that

$$
N\left(2^{n} f\left(\frac{x}{2^{n}}\right)-f(x), t\right) \geq N^{\prime}\left(\varphi(x, 2 x, x), \frac{t}{\sum_{j=0}^{n-1} 2^{j}|r|^{j+1}}\right)
$$

for all $x \in X$ and all $t>0$. So

$$
\begin{aligned}
N(f(x)-A(x), t) & \geq \min \left\{N\left(f(x)-2^{n} f\left(\frac{x}{2^{n}}\right),(1-\varepsilon) t\right), N\left(A(x)-2^{n} f\left(\frac{x}{2^{n}}\right), \varepsilon t\right)\right\} \\
& \geq N^{\prime}\left(\varphi(x, 2 x, x), \frac{t}{\sum_{j=0}^{n-1} 2^{j} \mid r r^{j+1}}\right) \\
& \geq N^{\prime}\left(\varphi(x, 2 x, x), \frac{(1-2|r|) \varepsilon t}{|r|}\right)
\end{aligned}
$$

for sufficiently large $n$ and for all $x \in X, t>0$ and $N$ with $0<N<1$. Since $N$ is arbitrary and $N^{N}$ is left continuous, we obtain

$$
N(f(x)-A(x), t) \geq N^{\prime}\left(\varphi(x, 2 x, x), \frac{(1-2|r|) t}{|r|}\right)
$$

for all $x \in X$ and $t>0$. It follows from (2.9) that

$$
\begin{aligned}
N & \left(2^{n+1} f\left(\frac{x+y+z}{2^{n+1}}\right)-2^{n} f\left(\frac{x}{2^{n}}\right)-2^{n} f\left(\frac{y}{2^{n}}\right)-2^{n} f\left(\frac{z}{2^{n}}\right), t\right) \\
& \geq N^{\prime}\left(\varphi\left(\frac{x}{2^{n}}, \frac{y}{2^{n}}, \frac{z}{2^{n}}\right), \frac{t}{2^{n}}\right) \\
& \geq N^{\prime}\left(\varphi(x, y, z), \frac{t}{2^{n}|r|^{n}}\right)
\end{aligned}
$$

for all $x, y, z \in X, t>0$ and all $n \in \mathbb{N}$. Since

$$
\lim _{n \rightarrow \infty} N^{\prime}\left(\varphi(x, y, z), \frac{t}{2^{n}|r|^{n}}\right)=1
$$

and so

$$
N\left(2^{n+1} f\left(\frac{x+y+z}{2^{n+1}}\right)-2^{n} f\left(\frac{x}{2^{n}}\right)-2^{n} f\left(\frac{y}{2^{n}}\right)-2^{n} f\left(\frac{z}{2^{n}}\right), t\right) \rightarrow 1
$$

for all $x, y, z \in X$ and all $t>0$. Therefore, we obtain in view of (2.18)

$$
\begin{aligned}
& N\left(2 A\left(\frac{x+y+z}{2}\right)-A(x)-A(y)-A(z), t\right) \\
& \geq \min \left\{N \left(A\left(\frac{x+y+z}{2}\right)-A(x)-A(y)-A(z)-2^{n+1} f\left(\frac{x+y+z}{2^{n+1}}\right)\right.\right. \\
& \left.-2^{n} f\left(\frac{x}{2^{n}}\right)-2^{n} f\left(\frac{y}{2^{n}}\right)-2^{n} f\left(\frac{z}{2^{n}}\right), \frac{t}{2}\right), \\
& \left.N\left(2^{n+1} f\left(\frac{x+y+z}{2^{n+1}}\right)-2^{n} f\left(\frac{x}{2^{n}}\right)-2^{n} f\left(\frac{y}{2^{n}}\right)-2^{n} f\left(\frac{z}{2^{n}}\right), \frac{t}{2}\right)\right\} \\
& =N\left(2^{n+1} f\left(\frac{x+y+z}{2^{n+1}}\right)-2^{n} f\left(\frac{x}{2^{n}}\right)-2^{n} f\left(\frac{y}{2^{n}}\right)-2^{n} f\left(\frac{z}{2^{n}}\right), \frac{t}{2}\right) \\
& \geq N^{\prime}\left(\varphi(x, y, z), \frac{t}{2^{n+1}|r|^{n}}\right) \rightarrow 1 \text { as } n \rightarrow \infty
\end{aligned}
$$


which implies

$$
2 A\left(\frac{x+y+z}{2}\right)=A(x)+A(y)+A(z)
$$

for all $x, y, z \in X$. Thus, A: $X \rightarrow Y$ is a mapping satisfying the Eq. $(0.1)$ and the inequality (2.11).

To prove the uniqueness, assume that there is another mapping $L: X \rightarrow Y$ which satisfies the inequality (2.11). Since $L(x)=2^{n} L\left(\frac{x}{2^{n}}\right)$ for all $x \in X$, we have

$$
\begin{aligned}
& N(A(x)-L(x), t)=\left(2^{n} A\left(\frac{x}{2^{n}}\right)-2^{n} L\left(\frac{x}{2^{n}}\right), t\right) \\
& \quad \geq \min \left\{N\left(2^{n} A\left(\frac{x}{2^{n}}\right)-2^{n} f\left(\frac{x}{2^{n}}\right), \frac{t}{2}\right), N\left(2^{n} f\left(\frac{x}{2^{n}}\right)-2^{n} L\left(\frac{x}{2^{n}}\right), \frac{t}{2}\right)\right\} \\
& \quad \geq N^{\prime}\left(\varphi\left(\frac{x}{2^{n}}, \frac{2 x}{2^{n}}, \frac{x}{2^{n}}\right), \frac{(1-2|r|) t}{|r| 2^{n+1}}\right) \\
& \quad \geq N\left(\varphi(x, 2 x, x), \frac{(1-2|r|) t}{|r|^{n+1} 2^{n+1}}\right) \rightarrow 1 \text { as } n \rightarrow \infty
\end{aligned}
$$

for all $t>0$. Therefore, $A(x)=L(x)$ for all $x \in X$, this completes the proof. $\quad \square$

Corollary 2.6. Let $X$ be a normed spaces and $\left(\mathbb{R}, N^{p}\right)$ a fuzzy Banach space. Assume that there exist real numbers $\theta \geq 0$ and $0<p<1$ such that a mapping $f: X \rightarrow Y$ satisfies the following inequality

$$
N\left(2 f\left(\frac{x+y+z}{2}\right)-f(x)-f(y)-f(z), t\right) \geq N^{\prime}\left(\theta\left(\|x\|^{p}+\|y\|^{p}+\|z\|^{p}\right), t\right)
$$

for all $x, y, z \in X$ and $t>0$. Then there is a unique additive mapping $A: X \rightarrow Y$ satisfying (0.1) and the inequality

$$
N(f(x)-A(x), t) \geq N^{\prime}\left(\theta\|x\|^{p}, \frac{2 t}{2^{r}+2}\right)
$$

Proof. Let $\phi(x, y, z):=\theta\left(\|x\|^{p}+\|y\|^{p}+\|z\|^{p}\right)$ and $|r|=\frac{1}{4}$. Applying Theorem 2.5, we get the desired result.

Theorem 2.7. Assume that a mapping $f: X \rightarrow Y$ satisfies (2.9) and $\phi: X^{2} \rightarrow Z$ is a mapping for which there is a constant $r \in \mathbb{R}$ satisfying $0<|r|<2$ and

$$
N^{\prime}(\varphi(2 x, 2 y, 2 z),|r| t) \geq N^{\prime}(\varphi(x, y, z), t)
$$

for all $x, y, z \in X$ and all $t>0$. Then there is a unique additive mapping $A: X \rightarrow Y$ satisfying (0.1) and the following inequality

$$
N(f(x)-A(x), t) \geq N^{\prime}(\varphi(x, 2 x, x),(2-|r|) t) .
$$

for all $x \in X$ and all $t>0$.

Proof. It follows from (2.13) that

$$
N\left(\frac{f(2 x)}{2}-f(x), \frac{t}{2}\right) \geq N^{\prime}(\varphi(x, 2 x, x), t)
$$


for all $x \in X$ and all $t>0$. Replacing $\mathrm{x}$ by $2^{n} x$ in (2.21), we obtain

$$
N\left(\frac{f\left(2^{n+1} x\right)}{2^{n+1}}-\frac{f\left(2^{n} x\right)}{2^{n}}, \frac{t}{2^{n+1}}\right) \geq N^{\prime}\left(\varphi\left(2^{n} x, 2^{n+1} x, 2^{n} x\right), t\right) \geq N^{\prime}\left(\varphi(x, 2 x, x), \frac{t}{|r|^{n}}\right) .
$$

So

$$
N\left(\frac{f\left(2^{n+1} x\right)}{2^{n+1}}-\frac{f\left(2^{n} x\right)}{2^{n}}, \frac{|r|^{n} t}{2^{n+1}}\right) \geq N^{\prime}(\varphi(x, 2 x, x), t)
$$

for all $x \in X$ and all $t>0$. Proceeding as in the proof of Theorem 2.5, we obtain that

$$
N\left(f(x)-\frac{f\left(2^{n} x\right)}{2^{n}}, \sum_{j=0}^{n-1} \frac{|r|^{j} t}{2^{j+1}}\right) \geq N^{\prime}(\varphi(x, 2 x, x), t)
$$

for all $x \in X$, all $t>0$ and all integers $n>0$. So

$$
N\left(f(x)-\frac{f\left(2^{n} x\right)}{2^{n}}, t\right) \geq N^{\prime}\left(\varphi(x, 2 x, x), \frac{t}{\sum_{j=0}^{n-1} \frac{r r^{j}}{2^{j+1}}}\right) \geq N^{\prime}(\varphi(x, 2 x, x),(2-|r|) t) .
$$

The rest of the proof is similar to the proof of Theorem 2.5. $\quad \square$

Corollary 2.8. Let $X$ be a normed spaces and $\left(\mathbb{R}, N^{\prime}\right)$ a fuzzy Banach space. Assume that there exist real numbers $\theta \geq 0$ and $0<p<\frac{1}{3}$ such that a mapping $f: X \rightarrow Y$ satisfies the following inequality

$$
N\left(2 f\left(\frac{x+y+z}{2}\right)-f(x)-f(y)-f(z), t\right) \geq N^{\prime}\left(\theta\left(\|x\|^{p} \cdot\|y\|^{p} \cdot\|z\|^{p}\right), t\right)
$$

for all $x, y, z \in X$ and $t>0$. Then there is a unique additive mapping $A: X \rightarrow Y$ satisfying (0.1) and the inequality

$$
N(f(x)-A(x), t) \geq N^{\prime}\left(\theta\|x\|^{p}, \frac{t}{2^{r}+2}\right)
$$

Proof. Let $\varphi(x, y, z):=\theta\left(\|x\|^{p_{1}} \cdot\|y\|^{p_{2}} \cdot\|z\|^{p_{3}}\right)$ and $|r|=1$. Applying Theorem 2.7, we get the desired result.

\section{Author details}

1Department of Mathematics, College of Sciences, Yasouj University, 75914-353 Yasouj, Iran ${ }^{2}$ Department of Mathematics, Firoozabad Branch, Islamic Azad University, Firoozabad, Iran ${ }^{3}$ Department of Mathematics, Research Institute for Natural Sciences, Hanyang University, Seoul 133-791, Korea ${ }^{4}$ Department of Mathematics, Daejin University, Kyeonggi 487-711, Korea

\section{Authors' contributions}

All authors conceived of the study, participated in its design and coordination, drafted the manuscript, participated in the sequence alignment, and read and approved the final manuscript.

\section{Competing interests}

The authors declare that they have no competing interests.

Received: 10 October 2011 Accepted: 19 December 2011 Published: 19 December 2011

\section{References}

1. Ulam, SM: Problems in Modern Mathematics. Science Editions. John Wiley, New York (1964)

2. Hyers, DH: On the stability of the linear functional equation. Proc Natl Acad Sci USA. 27, 222-224 (1941). doi:10.1073/ pnas.27.4.222 
3. Rassias, TM: On the stability of the linear mapping in Banach spaces. Proc Am Math Soc. 72, 297-300 (1978). doi:10.1090/S0002-9939-1978-0507327-1

4. Găvruta, P: A generalization of the Hyers-Ulam-Rassias stability of approximately additive mappings. J Math Anal Appl. 184, 431-436 (1994). doi:10.1006/jmaa.1994.1211

5. Skof, F: Local properties and approximation of operators. Rend Sem Mat Fis Milano. 53, 113-129 (1983). doi:10.1007/ BF02924890

6. Cholewa, PW: Remarks on the stability of functional equations. Aequationes Math. 27, 76-86 (1984). doi:10.1007/ BF02192660

7. Czerwik, S: Functional Equations and Inequalities in Several Variables. World Scientific, River Edge, NJ (2002)

8. Cho, Y, Saadati, R: Lattice non-Archimedean random stability of ACQ functional equation. Adv Diff Equ. 2011, 31 (2011). doi:10.1186/1687-1847-2011-31

9. Cădariu, L, Radu, V: On the stability of the Cauchy functional equation: a fixed point approach. Grazer Math Ber. 346, 43-52 (2004)

10. Cădariu, L, Radu, V: Fixed point methods for the generalized stability of functional equations in a single variable. Fixed Point Theory Appl 2008 (2008). Art. ID 749392

11. Eshaghi Gordji, M, Abbaszadeh, S, Park, C: On the stability of a generalized quadratic and quartic type functional equation in quasi-Banach spaces. J Inequal Appl 2009 (2009). Art. ID 153084

12. Eshaghi Gordji, M, Bavand Savadkouhi, M: Stability of mixed type cubic and quartic functional equations in random normed spaces. J Inequal Appl 2009 (2009). Art. ID 527462

13. Eshaghi Gordji, M, Bavand Savadkouhi, M, Park, C: Quadratic-quartic functional equations in RN-spaces. J Inequal Appl 2009 (2009). Art. ID 868423

14. Najati, A, Cho, Y: Generalized Hyers-Ulam stability of the Pexiderized Cauchy functional equation in non-Archimedean spaces. Fixed Point Theory Appl 2011 (2011). Art. ID 309026

15. Najati, A, Kang, J, Cho, Y: Local stability of the pexiderized Cauchy and Jensen's equations in fuzzy spaces. J Inequal Appl. 2011(78) (2011)

16. Park, C: Fixed points and Hyers-Ulam-Rassias stability of Cauchy-Jensen functional equations in Banach algebras. Fixed Point Theory Appl 2007 (2007). Art. ID 50175

17. Park, C: Generalized Hyers-Ulam-Rassias stability of quadratic functional equations: a fixed point approach. Fixed Point Theory Appl 2008 (2008). Art. ID 493751

18. Radu, V: The fixed point alternative and the stability of functional equations. Fixed Point Theory. 4, 91-96 (2003)

19. Saadati, $R$, Vaezpour, $M$, Cho, Y: A note to paper "On the stability of cubic mappings and quartic mappings in random normed spaces". J Inequal Appl 2009 (2009). Art. ID 214530

20. Saadati, R, Zohdi, MM, Vaezpour, SM: Nonlinear $\mathcal{L}$-random stability of an ACQ functional equation. J Inequal Appl 2011 (2011). Art. ID 194394

21. Katsaras, AK: Fuzzy topological vector spaces. Fuzzy Sets Syst. 12, 143-154 (1984). doi:10.1016/0165-0114(84)90034-4

22. Krishna, SV, Sarma, KKM: Separation of fuzzy normed linear spaces. Fuzzy Sets Syst. 63, 207-217 (1994). doi:10.1016/ 0165-0114(94)90351-4

23. Park, C: Fuzzy stability of a functional equation associated with inner product spaces. Fuzzy Sets Syst. 160, 1632-1642 (2009). doi:10.1016/j.fss.2008.11.027

24. Bag, T, Samanta, SK: Finite dimensional fuzzy normed linear spaces. J Fuzzy Math. 11, 687-705 (2003)

25. Cheng, SC, Mordeson, JN: Fuzzy linear operators and fuzzy normed linear spaces. Bull Calc Math Soc. 86, 429-436 (1994)

26. Karmosil, I, Michalek, J: Fuzzy metric and statistical metric spaces. Kybernetica. 11, 326-334 (1975)

27. Bag, T, Samanta, SK: Fuzzy bounded linear operators. Fuzzy Sets Syst. 151, 513-547 (2005). doi:10.1016/j.fss.2004.05.004

28. Cădariu, L, Radu, V: Fixed points and the stability of Jensen's functional equation. J Inequal Pure Appl Math 4(1) (2003). Art. ID 4

29. Diaz, J, Margolis, B: A fixed point theorem of the alternative for contractions on a generalized complete metric space. Bull Am Math Soc. 74, 305-309 (1968). doi:10.1090/50002-9904-1968-11933-0

30. Mihet, D, Radu, V: On the stability of the additive Cauchy functional equation in random normed spaces. J Math Anal Appl. 343, 567-572 (2008)

doi:10.1186/1029-242X-2011-140

Cite this article as: Kenary et al:: Fuzzy Hyers-Ulam stability of an additive functional equation. Journal of

Inequalities and Applications 2011 2011:140.

\section{Submit your manuscript to a SpringerOpen ${ }^{\circ}$ journal and benefit from:}

- Convenient online submission

- Rigorous peer review

- Immediate publication on acceptance

- Open access: articles freely available online

- High visibility within the field

- Retaining the copyright to your article

Submit your next manuscript at $\$$ springeropen.com 